\title{
APLICAÇÃO DO NOVO CURRÍCULO MíNIMO DO CURSO DE GRADUACCAO EM ENFERMAGEM OBSTÉTRICA DA FACULDADE DE ENFERMAGEM DA UNIVERSIDADE CATÓLICA DE MINAS GERAIS
}

\author{
Maria José da Silva * \\ Elvira Lúcio de Oliveira ** \\ M. ${ }^{a}$ Lídia de Queirós Rocha ** \\ Nair Rodrigues da Cunha **
}

\section{INTRODUÇÃO}

A FACULDADE DE ENFERMAGEM NA UNIVERSIDADE CATÓLICA DE MINAS GERAIS

Integrante de uma comunidade universitária, como uma das nove unidades de ensino e pesquisa da Universidade Católica de Minas Gerais, a Faculdade de Enfermagem, até o presente, é a única pertencente à área da saúde.

Dada esta situação, sente grande responsabilidade, não apenas pelo seu currículo, bastante diferente dos demais, como pelas características próprias do Curso de Enfermagem, e também pelas solicitações para estudos concernentes a programas, cursos, currículos e outros assuntos relacionados com o setor saúde.

Assim é que a Faculdade tem empregado todos os seus esforços para cooperar com a UCMG na implantação da Reforma Universitária, visando sempre ao atendimento de suas necessidades e à melhor qualidade do ensino profissional, para o que conta efetivamente com o apoio irrestritivo dos órgãos competentes da Universidade, o que facilita a sua integração na organização administrativa e didático-científica da mesma.

Decorrente dessa nova estruturação, o desenvolvimento dos diversos cursos assume nova significação para as unidades, pela integração das atividades didáticas numa dimensão global para toda a universidade.

* Diretora da Fac. de Enf. da UCMG (Relatora)

** Professoras da Fac. Enf. da UCMG (Colaboradoras) 


\section{DEPARTAMENTO DE ENFERMAGEM E OBSTETRICIA}

Consoante os princípios estabelecidos pela reforma universitária, surgiu a necessidade de reestruturar a organização departamental da universidade. Assim, depois de estudos neste sentido, o Conselho de Ensino e Pesquisa, através de duas resoluçōes, fixou norma transitória para escolha do Chefe de Departamento e estruturou os Departamentos que integram a UCMG.

Ficaram instituídos 16 Departamentos, dentre os quais o Departamento de Enfermagem e Obstetrícia. Em janeiro do corrente ano, por atos do Reitor, foram empossados os chefes dos respectivos lepartamentos, sendo que alguns exercerão "pro-tempore" os cargos de diretores das faculdades, como é o nosso caso. Assim, de acordo com a filosofia e os objetivos da UCMG, a formação profissional do enfermeiro, tendo em vista os preceitos estabelecidos na legislação em vigor, procura identificar-se com as exigências do desenvolvimento sócio-econômico, sempre em função das necessidades de saúde da comunidade.

A formação deste profissional, capacitado a desempenhar as tarefas mais complexas na enfermagem, incluindo a pesquisa e o magistério em nível superior, depende de uma conjugação de esforcos dos vários setores de atividades da universidade.

Portanto, dentro das perspectivas de uma programação global de estudos profissionais da UCMG, vejamos como se processa o deGesenvolvimento do Curso de Graduação em Enfermagem Obstetrícia.

\section{CONCURSO VESTIBULAR}

Em nossa universidade, o Concurso Vestibular Integrado, para acesso ao Primeiro Ciclo, é realizado em quatro áreas de conhecimentos afins, compreendendo, respectivamente, pré-opção para os seguintes cursos:

- Área A - Cursos de Enfermagem, Psicologia e Ciências

- Área B - Cursos de Engenharia

- Área C - Cursos de Filosofia, Ciências Religiosas, Pedagogia, Direito, Estudos Sociais e Letras

- Área D - Cursos de Serviço Social, Ciências Econômicas e Comunicação.

Para inscrição no Concurso Vestibular para os Cursos de Enfermagem, Psicologia e Serviço Social, exige-se em caráter obrigatório a aprovação em Laudo Psicológico realizado pelo Serviço de Orientação da Universidade Católica de Minas Gerais. Entretanto, o 
resultado deste Laudo Psicológico não influirá na classificação geral dos candidatos, assim como a contra indicação para estes cursos não impedirá o candidato de inscrever-se em outros cursos, para os quais não se faça esta exigência.

A classificação dos candidatos é feita pelo processo de normalização de escores, em ordem decrescente, até o limite de vagas oferecidas em cada curso da mesma área, excluindo-se os que tiverem resultado nulo em quaisquer provas. Assim, no requerimento de inscrição, o candidato indicará até duas pré-opções para os cursos de sua preferência, concorrendo em cada área, ao número de vagas oferecidas nos respectivos cursos da universidade.

Realiza-se o Concurso Vestibular em duas épocas anuais nos meses de janeiro e julho, sendo válido apenas para o período letivo correspondente, de acordo com o Edital.

\section{PRIMEIRO CICLO}

O Primeiro Ciclo da UCMG tem a duração de um semestre letivo, para todos os alunos da universidade, cujos estudos são dirigidos por uma Coordenação Central, em regime de cooperação com as unidades.

Além das finalidades previstas na Lei da Reforma Universitária Decreto_ Lei 464 de 11.02.69, pela sua condição especial, torna-se um Instrumento adequado de integração do estudante na vida universitária e de ampliação da cultura geral.

O Primeiro Ciclo compreende o estudo de disciplinas:

a) Fundamentais - disciplinas que integram o currículo de todos os cursos da mesma área.

b) Complementares - disciplinas específicas de cada curso.

Constituem disciplinas para o Primeiro Ciclo:

Fundamentais $=20$ créditos

Introdução aos Estudos Universitários

-2 créditos

Lógica e Introdução à Metodologia da Ciência

-4 créditos

História do Pensamento e do Mundo Contemporâneo

- 4 créditos

Áreas $A-C-D$

Āreas $B$

Psicologia -5 créditos

Química

- 5 créditos

Sociologia - 5 créditos

Introdução à Matemática superior

- 5 créditos 
Complementares $=4$ créditos

- Cursos de Enfermagem, Psicologia e Ciências

Física e Química - 2 créditos

Biologia - 2 créditos

- Cursos de Estudos Sociais, Comunicação, Serviço Social e Ciências Econômicas

Matemática Elementar - 4 créditos

- Cursos de Pedagogia, Direito, Filosofia e Ciências Religiosas e Letras

Português -2 créditos

Inglês ou Francês -2 créditos

- Cursos de Engenharia

Física - 4 créditos

Desta maneira, o aluno que obtiver os 24 créditos das disciplinas Fundamentais e Complementares, poderá matricular-se no Segundo Ciclo, no curso para o qual fez opção no Concurso Vestibular.

A reopção para outro curso ficará na dependência de vaga e de aprovação no exame de habilitação em discipiinas não cursadas no Primeiro Ciclo, quando for para curso de área diferente.

Para os cursos que exigem Laudo Psicológico positivo, a matrícula só poderá ser realizada mediante apresentação do citado Laudo.

\section{CURSO DE GRADUAÇÃO EM ENFERMAGEM E OBSTETRICIA}

A implantação gradual da Reforma Universitária da Universidade Católica de Minas Gerais tem levado as unidades a uma participação ativa em todos os estudos e trabalhos que vêm sendo desenvolvidos. Em conseqüência, surge um processo de reforma e adaptação de todos os cursos, revisão dos planos de ensino, visando a uma estruturação curricular bastante flexível, em vista do regime semestral e do sistema de matrícula por disciplinas.

O funcionamento do Primeiro Ciclo no $1^{\circ}$ semestre de 1972 proporcionou um pequeno recesso nas Unidades, pois os alunos aprovados no vestibular só vieram para as suas faculdades no $2 .^{\circ}$ semestre.

O novo currículo mínimo do Curso de Graduação em Enfermagem e Obstetrícia, aprovado conforme Parecer n. ${ }^{\circ}$ 163/72 do Conselho Federal de Educação em 28 de janeiro de 1972, deixou a cargo 
das instituições adotá-lo no mesmo ano, sendo obrigatório para os alunos matriculados em 1973.

A nossa Faculdade já vinha estudando adaptação do seu curso de Enfermagem e, por esta razão, a Comissão encarregada preparou o anteprojeto de acordo com o novo currículo, tendo em vista as exigências do Conselho Federal de Educação e a realidade da UCMG. Apresentado ao Conselho de Ensino e Pesquisa em 10 de maio de 1972, foi aprovado, conforme Resolução n.o 10/72.

A presente Resolução, entrando em vigor na mesma data, retroagiu seus efeitos a 15 de fevereiro de 1972, data do início do ano letivo na UCMG, quando foi, portanto, iniciado o Curso de Graduação em Enfermagem e Obstetrícia nos termos do Parecer n. ${ }^{\circ}$ 163/72.

\section{ORGANIZAÇÃO CURRICULAR}

O currículo pleno do Curso de Graduação em Enfermagem e Obstetrícia está estruturado em oito períodos semestrais assim distribuídos:

1. ${ }^{\circ}$ semestre

2..$^{\circ}$ e $3 .^{\circ}$ semestres

$4 .^{\circ}$ ao $7 .^{\circ}$ semestres

8..$^{\circ}$ semestre
- Primeiro Ciclo da UCMG

- Parte Pré-Profissional

- Tronco Profissional Comum

- Habilitação em: Enfermagem Mé-

dico Cirúrgica, Enfermagem Obstétrica e Enfermagem de Saúde Pública, como também para a modalidade de Licenciatura em Enfermagem.

As disciplinas pedagógicas do Curso de Licenciatura, de acordo com o Parecer n..$^{\circ}$ 672/69 e a Resolução n.0 09/69, do Conselho Feaeral de Educação, são ministradas pela Faculdade de Ciências Humanas e a prática de ensino é realizada na Faculdade de Enfermagem.

O sistema de crédito acadêmico corresponde a 15 horas aula em qualquer atividade programada no plano de ensino da disciplina no período letivo. Os créditos referentes a aulas práticas e estágios supervisionados são definidos pelo Colegiado de Cordenação Didática do Curso que, no caso da Enfermagem correspondem a 30 horas.

A distribuição das disciplinas pelos semestres letivos está relacionada com os pré e co-requisitos e com o número de créditos estabelecidos por período letivo, o máximo de 30 e o mínimo de 12 . Entretanto, não pode ser considerada ideal essa distribuição, apesar dos critérios adotados, porque o currículo se encontra em fase inicial de implantação. 
O número de vagas é tomado por turmas, que são cinquenta, e, somente em casos especiais, o aluno se inscreve em disciplinas de várias turmas, embora o regime de matrículas por disciplinas esteja estruturado na universidade.

\section{CURRICULO (Anexo)}

\section{ESTÁGIOS}

A formação profissional do enfermeiro, incluindo todas as habilitaçōes;, exige o Estágio Sưpervisionado em hospitais e outros serviços sanitários, com carga horária não inferior a $1 / 3$ da correspondente ao ensino de disciplinas profissionalizantes.

Um campo de estágio adequado é muito importante e leva o aluno a adquirir certas experiências práticas nas áreas básicas de enfermagem, favorecendo a integração do ensino e da pesquisa ao desempenho da prática profissional.

Ao planejar o estágio para estas disciplinas, imediatamente são relacionados inúmeros fatores desfavoráveis que às vezes são encontrados em muitos serviços, tornando-se inadequados para compos de estágios de nossos alunos. Assim, a deficiência numérica e qualitativa de pessoal de enfermagem, a falta de material e equipamentos, a própria filosofia de trabalho da instituição constituem fatores preponderantes que refletem na inadequação entre ensino teórico e prática profissional. Estas dificuldades, freqüentes em nossos serviços, constituem barreiras ao bom aproveitamento dos alunos, estão exigindo das duas partes, enfermeiras de campo e profesoras de enfermagem, um melhor entrosamento, um estudo em conjunto, o que resultará, sem dúvida, em melhoria sensível do campo para a prática de alunos, repercutindo favoravelmente na boa assistência de enfermagem aos pacientes, os quais constituem o objetivo primordial de nossa profissão.

A nossa Faculdade funciona no prédio da Santa Casa, um hospital geral que possui quase todas as clínicas gerais e especializadas. Apesar de nem todas oferecem condições para estágios, temos nctado que vem melhorando dia a dia a receptividade para os alunos, especialmente por parte das profissionais mais jovens, que continuam o contato com a escola através dos estágios dos alunos.

$E$ isto para nós é de um valor imenso, pois há grande enriquecimento para todos, alunos, professores e enfermeiras de serviços; c também assim passamos a nos esforçar para a programação das atividades nesta adequação teoria - prática, numa tentativa de levar o aluno a aplicar nos estágios os seus conhecimentos adquiridos em aulas. Vimos sentindo que, mesmo estágio não favorecendo 
todas as condições, é possível despertar a iniciativa e a criatividade do aluno em diversas oportunidades e situações encontradas na prática profissional.

Não ignoramos ainda que, além do entrosamento com os serviços, a relação docente-aluno é de grande importância para o bom aproveitamento dos estágios. Em nosso caso, esta relação varia entre uma docente para oito alunos em Introdução à Enfermagem, variando também com o progresso manifestado pelos alunos durante OS estágios, chegando a uma docente para doze alunos em outras disciplinas, como Administração aplicada à Enfermagem. Ainda não dispomos de docentes especializadas para as respectivas disciplinas, mas, apesar das dificuldades de cursos de especialização ou falta de oportunidade para a freqüência de cursos em outros estados, estamos nos valendo dos cursos oferecidos pela Comunidade.

As profissionais novas, mesmo com pouca experiência, têm demonstrado grande facilidade de entrosamento e adaptação ao campo de ensino, sendo que a orientação às docentes recém-admitidas constitui grande ajuda ao seu desenvolvimento profissional.

\section{CONCLUSÕES}

Este é o currículo que a Faculdade de Enfermagem Universidade Católica de Minas Gerais vem procurando aplicar, dentro de suas limitações de seus recursos humanos e materiais.

Há muito ainda por aprender e por realizar. O currículo não importa apenas na organização e distribuição das disciplinas, mas abrange todas as atividades de alunos e professores, numa integração do ensino à realidade dos serviços de enfermagem.

A Reforma Universitária, gradativamente concretizada no País, oferece novas perspectivas do ensino voltado para o aluno e mais adequado à reais necessidades da comunidade, o que sem dúvida, fortalecerá o Curso de Graduação em Enfermagem e Obstetrícia e, consequentemente, melhor preparo do corpo docente, para uma atuação segura e eficiente, em face dos novos critérios adotados no ensino da enfermagm.

\section{RECOMENDAÇÕES}

Às diretoras e docentes de enfermagem:

1. que procurem o melhor entrosamento com os serviços de enfermagem para que enfermeiras docentes e enfermeiras de campo conjuguem todos os esforços, visando à maior adequação entre o ensino e a sua aplicação no campo profissional; 
2. que se interessem por conhecer e compreender as implicações decorrentes da reforma em vista da formação profissional do enfermeiro;

3. que através da monitoria, selecionando e orientando alunos que demonstrem aptidões para o magistério, encontrem meios de prover pessoal e de estimular a carreira docente de enfermagem.

\section{BIBLIOGRAFIA}

1. ANUARIO DA UNIVERSIDADE CATÓLICA DE MINAS GERAIS. Belo Horizonte, UCMG, 1969.

2. Arquivos da Secretaria da Faculdade de Enfermagem.

3. ARTACHO, Stella Ir. \& FURTADO, Lilia Ir. História da Escola de Enfermagem Hugo Werneck. Revista Brasileira de Enfermagem, Rio de Janeiro, 15(2): 84, abr., 1962.

4. BRASIL. Conselho Federal de Educação. Parecer n. ${ }^{\circ} 163 / 72$.

5. BRASIL. Conselho Federal de Educação. Parecer n. $.^{\circ} 672 / 69$.

6. BRASIL. Conselho Federal de Educação. Parecer n. ${ }^{\circ} 09 / 69$.

7. BRASIL. Ministério da Educação e Cultura. P. Brasil. Instituto Nacional de Estudos Pedagógicos. Ensino Superior; Coletânea de legislação básica, 1969.

8. CONSELHO DE REITORES DAS UNIVERSIDADES BRASILEIRAS. O Ciclo Básico; 1 ciclo geral de estudos. Rio de Janeiro, 1969. 60 p.

9. MINAS GERAIS. UNIVERSIDADE CATÓLICA DE Estatuto.

10. MINAS GERAIS. UNIVERSIDADE CATÓLICA DE Conselho de ensino e pesquisa. Resoluções $\mathrm{n} .{ }^{\circ}$ 04/70, 07/71, 08/71, 09/71. 02/72, 08/72, 16/72, 21/72, 02/73.

11. MINAS GERAIS. UNIVERSIDADE CATÓLICA DE Conselho Universitário.

12. OLIVEIRA, M. Ivete Ribeiro - A reforma universitária e o curso de graduação para enfermeiras. Revista Brasileira de Enfemagem, Rio de Janeiro, 20(4): 35, ago., 1967. 


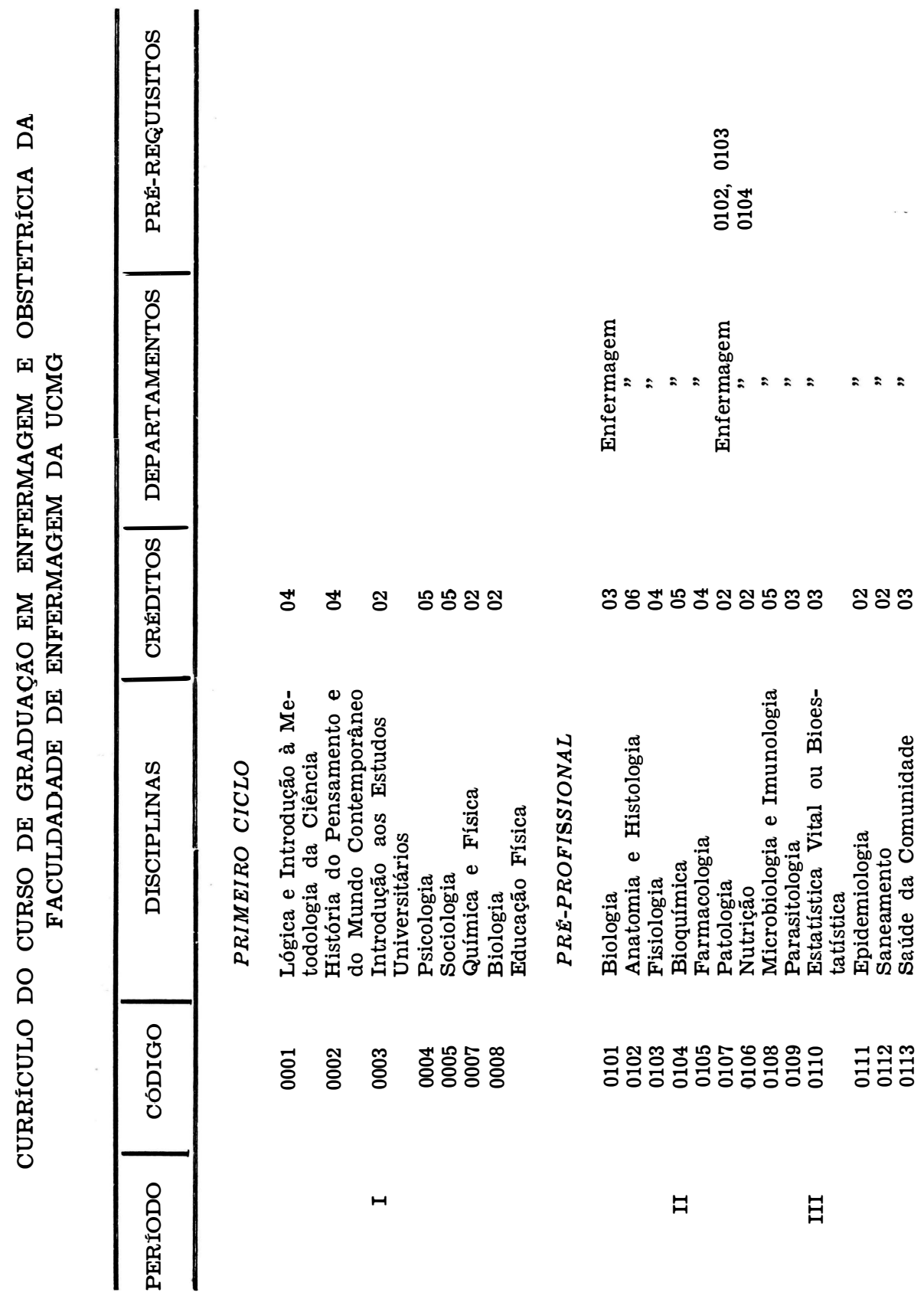


เ્ำ

ठ̊

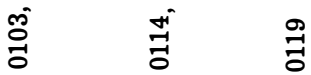

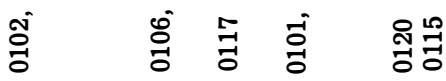

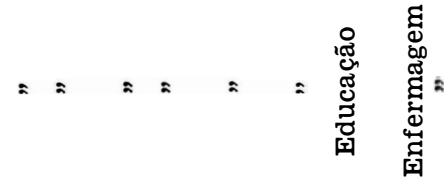

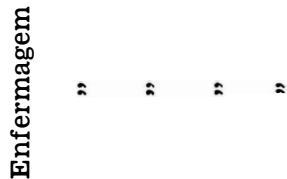

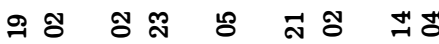

ชิ

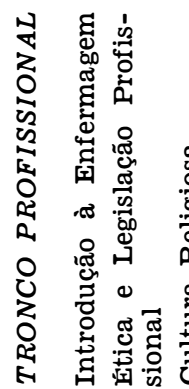
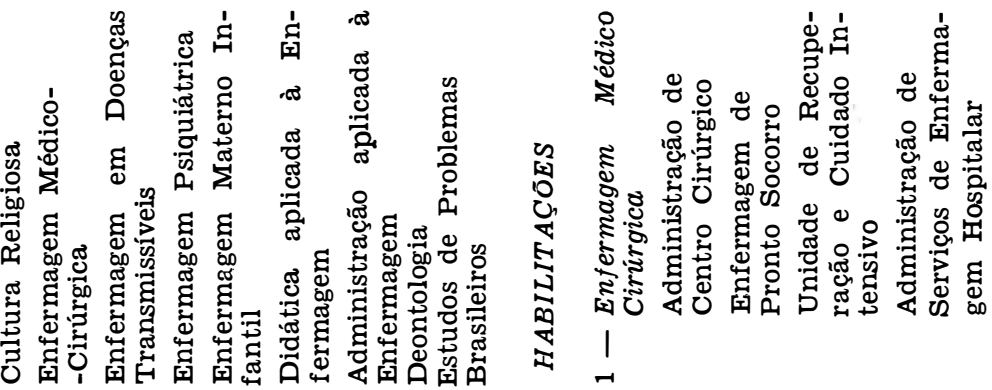

苛先 壵

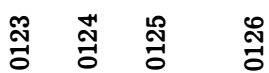

$P \quad P \quad 5$

$\stackrel{\text { 号 }}{P}$

宫 


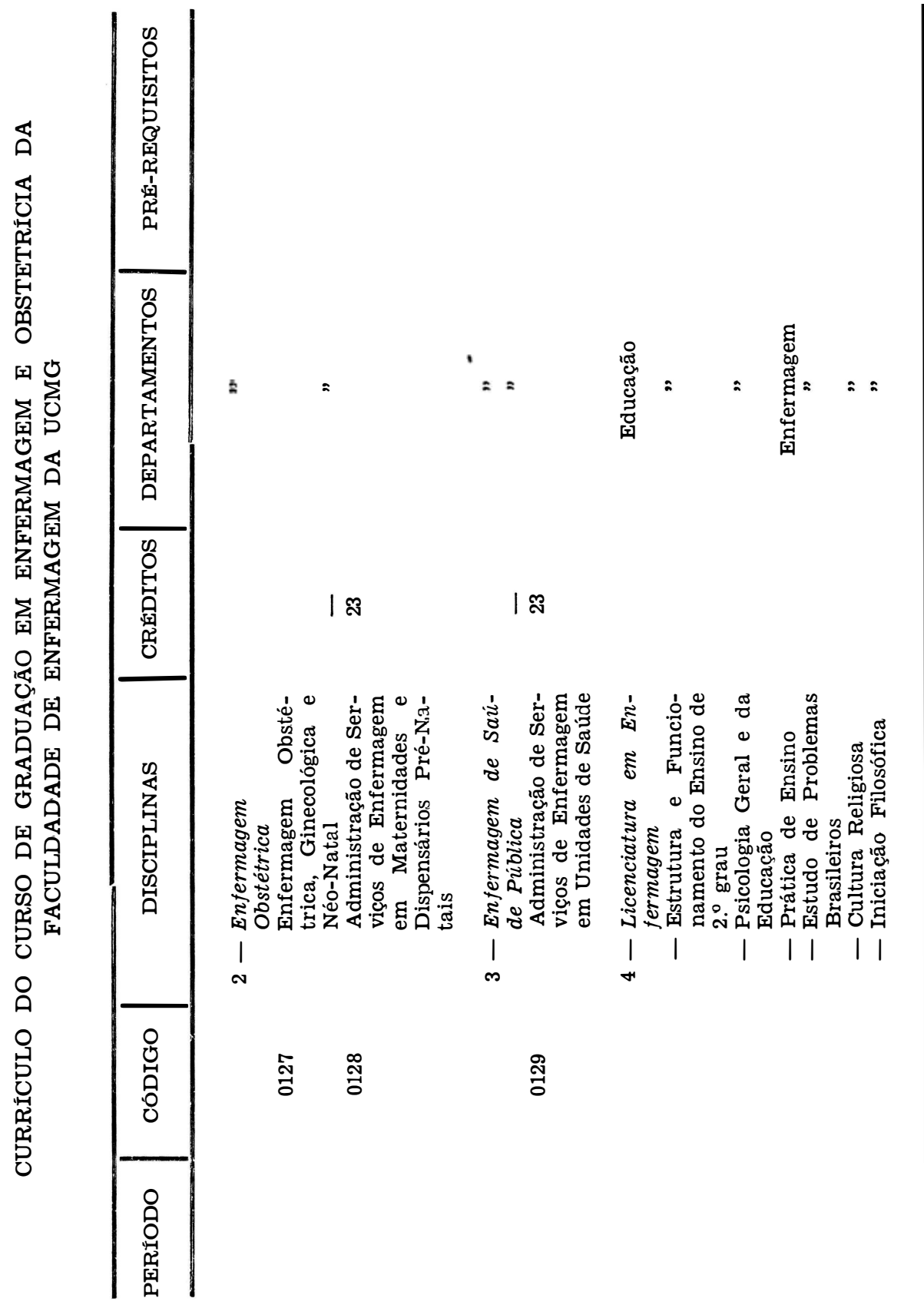

